\title{
Cenlestao
}

\section{Modelos e etapas para a gestão da informação: uma revisão sistemática de literatura}

\author{
Frederico Giffoni de Carvalho Dutra \\ Doutorando; Universidade Federal de Minas Gerais, Belo Horizonte, MG, Brasil; \\ E-mail: fgcdutra@gmail.com \\ Ricardo Rodrigues Barbosa \\ Doutor; Universidade Federal de Minas Gerais, Belo Horizonte, MG, Brasil; \\ E-mail: rrbarb@gmail.com
}

\begin{abstract}
Resumo: O artigo relata os resultados de uma revisão sistemática da literatura sobre modelos e etapas utilizados para a gestão da informação. Foi realizada pesquisa bibliográfica em três idiomas (português, espanhol e inglês) para se analisar a produção científica sobre conceitos relativos a fontes de informação, gestão da informação, bem como os critérios e modelos utilizados para sua gestão. Após pesquisa em artigos e demais publicações no período de 1972 a 2019, os resultados apontam a existência de 44 modelos. Foram também identificados os critérios mais frequentemente citados. Constatou-se a existência de 38 termos distintos, destacando-se os seguintes: Coleta/Aquisição/Acesso/Obtenção, Distribuição/Disseminação/Difusão, Uso/Utilização, Armazenamento/Registro, Identificação das necessidades/requisitos/exigências, Organização, Interpretação/Análise, Tratamento/Sistematização, Descarte, Recuperação.
\end{abstract}

Palavras-chave: Gestão da informação. Modelos. Etapas. Fontes de informação.

\section{Introdução}

A explosão informacional que caracteriza a sociedade contemporânea representa, ao mesmo tempo, oportunidades e desafios para as empresas. Se por um lado existe uma profusão de informações sobre os mais diversos aspectos do ambiente concorrencial, por outro ela se mostra como um grave problema a ser resolvido devido à grande quantidade de lixo informacional e falta de padronização (CENDÓN, 2000).

Tamanha informação disponível culmina com o que Bawden e Robinson (2009) denominam "patologias da informação", as quais são provocadas pela quantidade e diversidade da informação disponível. Nesse contexto, o tomador 
de decisões necessita de informações relevantes, mas, antes de tudo, precisa de dispositivos de filtros (SAVOLAINEN, 2007). A medição da qualidade é uma forma de classificar e identificar as informações que podem atender melhor aos interesses e necessidades dos usuários. Além disso, são necessários procedimentos ou critérios para organizar e gerir tais informações.

A necessidade de se obter informações em tempo hábil e, sobretudo, confiáveis e estruturadas, nos coloca diante do seguinte questionamento: quais os critérios/etapas e modelos utilizados para uma adequada gestão da informação?

Dessa forma, o objetivo deste estudo é identificar e estudar os modelos e as etapas de gestão da informação disponíveis na literatura.

Torna-se necessário, ainda, compreender conceitos básicos como fontes de informação e seus tipos; selecionar estudos e modelos referentes aos critérios, às etapas e aos modelos de gestão da informação e, por fim, realizar inferências a respeito dos resultados coletados.

\section{Metodologia}

Como metodologia para este estudo foi realizada uma revisão sistemática de literatura para aprofundar o conhecimento sobre os modelos e as etapas referentes à gestão da informação. A pesquisa foi desenvolvida no período de novembro de 2017 a julho de 2019 por meio de artigos obtidos no Portal de Periódicos Capes, na Base de Dados Referencial de Artigos de Periódicos em Ciência da Informação (Brapci), no Google Acadêmico, no banco de dissertações e teses da Universidade Federal de Minas Gerais (UFMG), em livros, sites de bibliotecas, revistas e publicações recuperadas no buscador Google.

Para a recuperação das publicações referentes ao tema foram utilizados termos nas línguas portuguesa, inglesa e espanhola, conforme apresentado a seguir:

a) Português: etapas de gestão da informação, modelos de gestão da informação, gestão estratégica da informação, critérios para gestão da informação; 
b) Inglês: information management stages, information management models, strategic information management, information management criteria;

c) Espanhol: pasos para gestión de información, modelos de gestión de información, gestión estrategico de información, criterios para gestión de información.

Por meio dessa pesquisa, foi possível sintetizar o trabalho de 44 autores, no período de 1988 a 2017. Apesar dos primeiros modelos de gestão da informação encontrados surgirem na década de 1980, vale ressaltar que a revisão de literatura abrangeu o período de 1972 a 2019.

\section{Gestão estratégica da informação}

A informação é um recurso valioso para o processo de tomada de decisão organizacional. Porém, para que a informação seja eficaz, ela necessita ser administrada e gerenciada (CALAZANS, 2006, p. 70). O acompanhamento e cumprimento adequado das etapas de gestão da informação são fatores críticos para a eficiência e a eficácia no âmbito decisório. Para Mendonça e Varvakis (2018), a sobrevivência das organizações depende da habilidade de gerir as informações e gerar conhecimento aos executivos ou gestores nas tomadas de decisão. A partir do entendimento dos fluxos informacionais, é possível desenvolver ações de melhorias que diretamente se relacionam ao sucesso do processo decisório e, consequentemente, ao sucesso empresarial.

A evolução da importância atribuída à gestão da informação nas organizações deu-se da seguinte maneira: na década de 1950, considerava-se a informação um requisito burocrático necessário, que contribuía para reduzir o custo do processamento de muitos papéis; nos anos 1960 e 1970, via-se a informação como um suporte aos propósitos gerais da empresa, que auxiliava no gerenciamento de diversas atividades; a partir das décadas de 1970 e 1980, passou-se a compreender a informação como um fator de controle e gerenciamento de toda a organização, que ajudava e acelerava os processos de tomada de decisão; e, da década de 1990 até os dias atuais, passou-se a 
reconhecer a informação como um recurso estratégico, uma fonte de vantagem competitiva para garantir a sobrevivência da empresa (LAUDON; LAUDON, 1996).

Em 1979, o autor John Diebold escreveu um artigo intitulado 'Information resource management-The new challenge', em que se introduzia a ideia de que a informação devia se manejar como um recurso fundamental na empresa. Em 1981, por meio do livro 'Information Resource management _opportunities and strategies for the 1980s', Synott y Gruber aprofundaram tal ideia. Ambos os trabalhos inauguraram uma linha de pensamento baseada na convicção de que a informação deveria receber uma maior consideração por parte das empresas (ARTILES VISBAL, 2009).

De acordo com Vance (2000), a administração reconhece a importância estratégica que a criação e o uso da informação exercem sobre o desempenho de uma empresa. Choo (2003) ainda afirma que sem uma visão clara de como a organização cria, transforma e usa a informação, não será possível administrá-la.

Os termos "sociedade da informação" ou "sociedade do conhecimento" têm sido frequentemente empregados para interpretar as rápidas transformações que vêm ocorrendo na economia e na sociedade em praticamente todo o mundo. Os impactos causados pelas tecnologias de informação e comunicação refletem a importância que as atividades de informação vêm adquirindo, influenciando fortemente o crescimento e o desempenho econômico de nações e organizações, conforme destaca Galvão (1999).

Barbosa (1997) afirma que, do ponto de vista da prática gerencial, são inúmeros os desafios encontrados pelos profissionais para se informar a respeito do que acontece no entorno de suas empresas. Por um lado, é difícil selecionar, dentre a crescente multiplicidade de fontes de informação existentes, aquelas que contêm, de fato, o que se necessita. Por outro lado, a farta disponibilidade de informações não assegura, em si, que elas sejam efetivamente valiosas para seus usuários. De fato, antes de se transformarem em base sólida para o processo decisório, essas informações precisam ser analisadas e discutidas pela cúpula decisória das organizações. 
Borges e Carvalho (1998) afirmam que a cada dia torna-se mais claro o papel econômico da informação como insumo para o desenvolvimento de produtos, captação de recursos, conhecimento de mercado e sobrevivência de muitas empresas.

De acordo com Rezende (2002), o que determina a excelência de uma empresa é a habilidade com que ela coleta, organiza, analisa e implementa mudanças a partir de informações. A esse processo se dá o nome de gestão da informação. Segundo Lesca e Almeida (1994), a gestão estratégica da informação consiste no uso da informação com fins estratégicos para obter vantagem competitiva.

Para Bergeron (1996), é a estratégia utilizada pelas organizações visando a solucionar seus problemas informacionais por meio da disponibilização de informações corretas para uma determinada pessoa ou grupo de pessoas, no momento e na forma adequados.

Para alguns pesquisadores como Oliveira e Bertucci (2003), a gestão da informação envolve o processo da informação, com os objetivos de: promover a eficiência, de forma a organizar e suprir as demandas por informação vindas externamente e internamente; planejar políticas de informação; desenvolver e manter sistemas e serviços de informação; melhorar o fluxo de informação e o controle da tecnologia da informação.

Segundo Tarapanoff (2006), informação no contexto da gestão da informação refere-se a todos os tipos de informação de valor, tanto de origem interna quanto de externa à organização. É a ideia de informação como ferramenta estratégica. Essa nova visão fez com que empresas instituissem estruturas formais para cuidar da gestão dos recursos informacionais (ligadas ao alto escalão). Dessa forma, o termo passa de gestão da informação para gestão dos recursos informacionais, cuja finalidade é acompanhar processos, apoio à tomada de decisão estratégica e obtenção de vantagem competitiva frente à concorrência.

Entretanto, Valentim (1997) afirma que a classe empresarial não consegue visualizar a importância do suporte informacional como auxiliar no domínio dos processos organizacionais. A falta de visualização pode estar 
relacionada à má adequação ou indisponibilidade de mecanismos de gestão da informação, portanto, se faz necessário que o profissional que atue nesse setor esteja atento para as etapas dos processos de tomada de decisão, assim como naqueles que influenciam a produção e uso da informação.

Ainda na opinião de Valentim (2002), as organizações são formadas por três ambientes: o primeiro está ligado ao próprio organograma, isto é, às interrelações entre as diferentes unidades de trabalho como diretorias, gerências, divisões, departamentos, etc. O segundo está relacionado à estrutura de recursos humanos, isto é, às relações entre pessoas das diferentes unidades de trabalho. $\mathrm{O}$ terceiro e último é composto pela estrutura informacional, ou seja, geração de dados, informação e conhecimento pelos dois ambientes anteriores. A partir do reconhecimento desses três ambientes, pode-se mapear os fluxos informais de informação existentes na organização, assim como é possível estabelecer fluxos formais de informação para consumo da própria organização.

O mapeamento de um fluxo de informação é a representação do caminho percorrido pela informação por meio de seus canais, bem como dos agentes responsáveis pela criação, pela movimentação, pelo armazenamento e pela distribuição dessas informações (ARAÚJO et al, 2018). A figura a seguir ilustra o exposto.

Figura 1 - Ambientes organizacionais
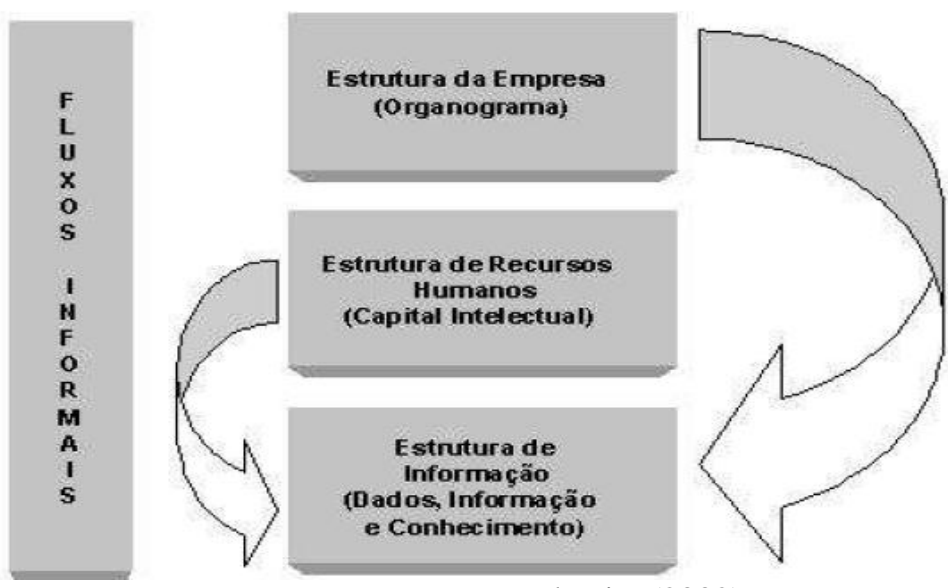

Fonte: Valentim (2002).

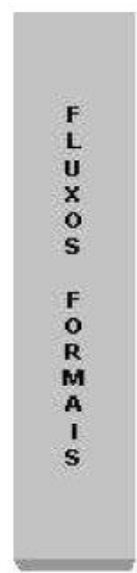

$F$
L
U
$X$
0
S
F
0
$R$
M
A
I
S

Os fluxos formais atuam na estrutura física da empresa, ou seja, estão relacionados ao próprio organograma, onde ocorrem interrelações entre os 
setores. Já os fluxos informais são constituídos a partir da relação entre as pessoas das diferentes áreas/setores da organização. Ambos os fluxos são subsidiados pelos insumos dados, pela informação e pelo conhecimento, contribuindo para a constituição dos ambientes informacionais (PACHECO; VALENTIM, 2010).

Para gerenciar esses fluxos informacionais, quer formais ou informais, Valentim (2002) afirma que é necessário realizar algumas ações integradas objetivando prospectar, selecionar, filtrar, tratar e disseminar todo o ativo informacional e intelectual da organização, incluindo desde documentos, bancos e bases de dados etc., produzidos interna e externamente à organização até o conhecimento individual dos diferentes atores existentes na organização.

Na opinião de Fonseca, Barbosa e Pereira (2019), se do ponto de vista pessoal é grande o desafio de conviver com a crescente avalanche de dados produzidos diariamente, no ambiente organizacional a complexidade é ainda maior. Nesse contexto, o fluxo informacional que permeia as empresas exige dos profissionais maior agilidade, assertividade para acessar e interpretar dados, gerar informações, compartilhar conhecimento e tomar decisões. Nesse sentido, destaca-se a relevância da informação e do conhecimento na esfera organizacional. Apropriar-se de informações, saber acessá-las e usá-las, bem como garantir a retenção e disseminação do conhecimento dentro das empresas, de forma ágil e estratégica, não é um desafio simples.

Marchiori (2002) enfatiza que a gestão da informação engloba ainda a sinergia entre a tecnologia da informação e comunicação e os recursos/conteúdos informativos, visando ao desenvolvimento de estratégias e à estruturação de atividades organizacionais.

Segundo afirmação de Rodrigues e Blattman (2014), mais recentemente, autores como Rodrigues e Tomaél (2008), Rossetti (2008), Barbosa, Sepúlveda e Costa (2009), Marteleto (2010) e Sugahara e Vergueiro (2010) passaram a tratar da gestão da informação e das redes sociais digitais/virtuais. Na análise dos estudos sobre as redes sociais, percebe-se a necessidade de conhecer os elementos nela envolvidos, o tipo de informação de que necessitam, quem as utilizam e a diversidade dos fluxos informacionais existentes. Nesses ambientes, 
criam-se redes de relacionamentos, de inovação e conhecimento, informais e de negócios. E a formação de redes nas organizações é consequência da confiança mútua entre os autores envolvidos nas atividades.

Por meio dessa confiança, estabeleceu-se o que Rossetti (2008) chamou de 'era da inteligência em redes'. Nesse contexto, a gestão da informação é sustentada por imensas bases de dados, pela tecnologia da informação e comunicação e por ferramentas web de compartilhamento e colaboração (blogs, wikis, folksonomia, ontologia, hipertextos e tecnologia RSS). Sendo assim, numa análise das redes sociais e dos fluxos de informação, é importante desenvolver a capacidade de perceber a informação como informação, entender a estrutura da rede e os tipos de relacionamentos dessa estrutura.

$\mathrm{Na}$ opinião de Chamusca e Carvalhal (2011), desde quando o conhecimento começou a ser sinônimo de poder, o ser humano e, principalmente, suas organizações, têm buscado formas de conhecer melhor o público consumidor a fim de conquistá-lo, tarefa que se tornou mais fácil, pelo menos aparentemente, a partir do uso da informática para a mineração, o monitoramento e a mensuração dos dados. $\mathrm{O}$ mesmo se pode dizer das métricas utilizadas no monitoramento e na mensuração em redes sociais, por exemplo.

Para Recuero (2009), as redes sociais na internet alteram de forma expressiva o fluxo de informações na sociedade, pois permitem que todo ator seja um potencial emissor das informações, além de facilitar sua circulação. Segundo Barbosa et al (2018), o fluxo de informação proveniente das redes sociais pode ser utilizado internamente nas organizações como insumo para o processo de inteligência competitiva e gestão do conhecimento.

Os argumentos anteriores enfatizam a importância de uma adequada gestão dos recursos informacionais de uma organização como fator de competitividade. Esta informação, que possui diversas fontes (inclusive as digitais) e diversos mecanismos para coleta, será utilizada como base para tomada de decisão, relacionamento, elaboração de novos produtos, serviços, processos, entre outros. 


\subsection{Fontes de informação: conceitos e classificação}

Para Ferreira (2018), fonte é aquilo que origina ou produz, origem, procedência, proveniência, documento ou pessoa que fornece uma informação, texto de autor considerado como referência, texto ou documento original usado como referência.

Para Cunha (2001), o conceito de fonte de informação é muito amplo, pois pode abranger manuscritos e publicações impressas, além de objetos, como amostras minerais, obras de arte ou peças manuscritas. Há uma enorme variedade de material informacional com funções diferenciadas e em diferentes suportes de armazenagem (do meio impresso ao eletrônico). Araújo e Fachin (2015) corroboram com a afirmativa anterior, pois segundo os autores é preciso reconhecer que as fontes de informações não são apenas aquelas que estão disseminadas em suportes convencionais, já que na história houve registros como as pinturas rupestres, as pinturas de momentos e acontecimentos realizadas por artistas e até mesmo a fotografia impressa.

É sabido que são inúmeros os meios para munir com informações pesquisadores e empresas. $\mathrm{O}$ advento da internet ampliou de maneira exponencial essa gama de fontes. Nos atuais ambientes de negócios, Fonseca, Barbosa e Pereira (2019) afirmam que, para uma empresa desenvolver-se de forma competitiva, é preciso que ela monitore e gerencie informações dos ambientes interno e externo.

Uma alternativa bastante utilizada por estes públicos é identificar a origem das informações obtidas. Tal identificação funciona como uma espécie de mapeamento/rastreamento dos principais meios utilizados para obtenção de informação.

Dutra (2014), após extensa análise de modelos pertencentes a outros pesquisadores, elaborou o modelo de classificação de fontes de informação a seguir: 
Figura 2 - Modelo de classificação das fontes de informação

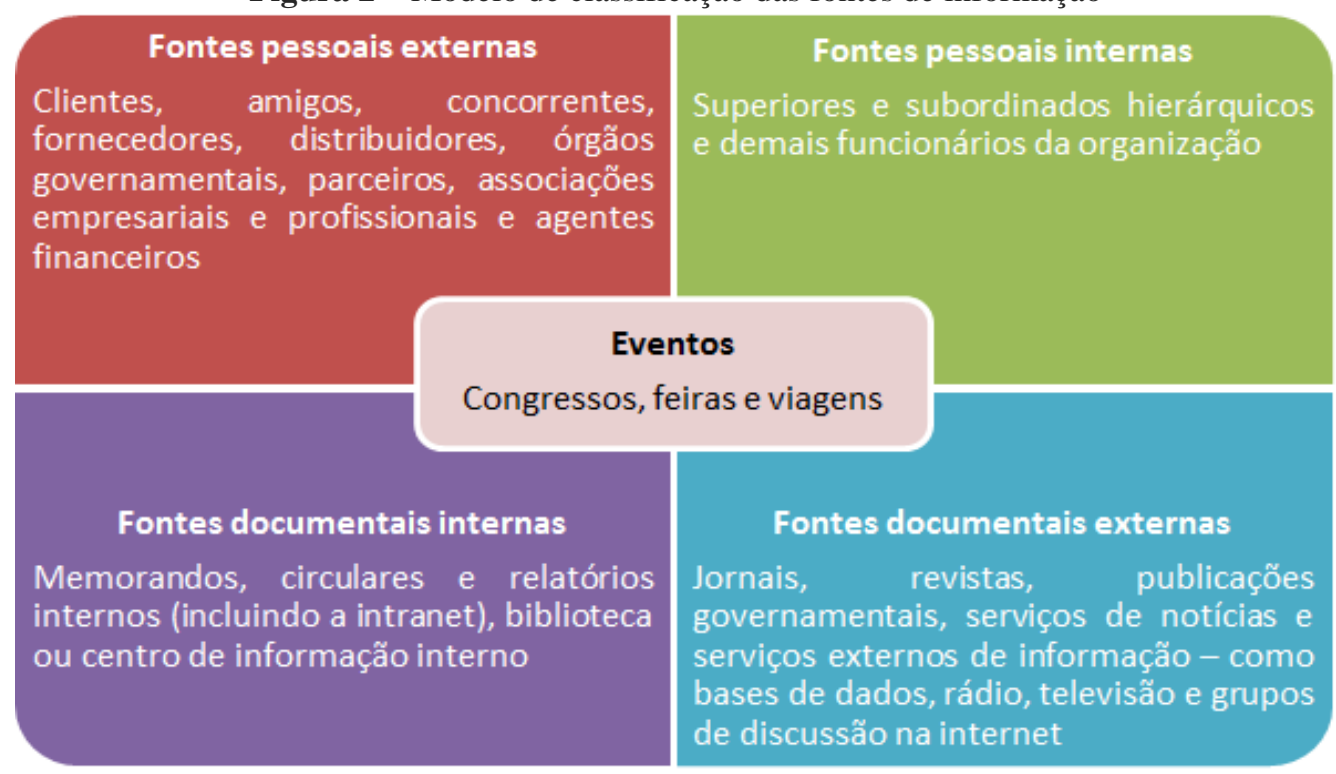

Fonte: Adaptado de Dutra (2014).

É possível perceber que o modelo anterior contemplava a internet e grupos de discussão como fontes de informação. Entretanto, à época, não havia a noção da dimensão que as redes sociais ocupariam no contexto corporativo e pessoal. Dessa forma, é plausível fazer uma adaptação ao modelo, inserindo as redes e mídias sociais aos tipos de fontes documentais externas e até mesmo internas, no caso de empresas que já desenvolveram tais soluções como meio de comunicação interna.

\subsection{Estudos sobre modelos e etapas de gestão da informação}

Para que as organizações tomem o caminho do conhecimento, faz-se necessário, no primeiro momento, criar meios para compartilhar a informação e o conhecimento produzido, o que pressupõe o estabelecimento de métodos e critérios de gestão (TAKEUCHI; NONAKA, 2008).

Muitas técnicas e modelos de gestão da informação têm sido desenvolvidos e aplicados, seja em teoria ou na prática, tanto pela Ciência da Informação como pela Computação e Administração (BARBOSA, 2008; MARCHIORI, 2002). Nesta última, especificamente, que tem interesse pelos aspectos informacionais no que se refere à tomada de decisões em organizações, Martins (2014) alega que foram desenvolvidas técnicas e modelos de gestão da 
informação visando maximizar as potencialidades da informação, o desempenho organizacional e a tomada de decisão.

Como todo processo, a gestão da informação é composta por etapas que, se utilizadas corretamente, podem trazer benefícios, como a gerência de uma informação de forma integrada, coerente, eficiente e eficaz para que a informação chegue às pessoas certas, no local correto, no tempo certo, no formato adequado, no custo certo, facilitando a tomada de decisão, elevando ao máximo a qualidade, a disponibilização, a utilização e o valor da informação (SILVA, 2006).

Comumente, as etapas da gestão da informação são denominadas de modelos. Inicialmente, os modelos, em geral, buscam a formalização do universo por meio de meios de expressões controláveis pelo ser humano; derivam da necessidade humana de entender a realidade aparentemente complexa do universo envolvente. São, portanto, representações simplificadas e inteligíveis do mundo, que permitem vislumbrar características essenciais de um domínio ou campo de estudo (SAYÃO, 2001).

Segundo Chorley e Haggett (1975), um modelo é uma estruturação simplificada da realidade, que apresenta, supostamente, características ou relações sob forma generalizada. Os modelos podem ser aproximações altamente subjetivas, por não incluírem todas observações, mensurações e medições associadas, mas, como tais, são valiosas por ocultarem detalhes secundários e permitirem o aparecimento dos aspectos fundamentais da realidade.

A representação do mundo por modelos ainda está longe de traduzir ou interpretar integralmente a complexidade da realidade dos fenômenos, motivo pelo qual vários modelos são propostos sob a pretensão de substituir formatos anteriores e menos completos. Quanto mais abrangente um modelo se apresentar, maior será a chance de substituir um formato prévio. Entretanto, a modelização é uma prática comum no ambiente científico e na Ciência da Informação. A informação - seu objeto de estudo - também tem sua representação por modelos (MARTINS; CIANCONI, 2013). 
Para que se compreenda a maneira de se gerir a informação, é necessário compreender de que maneira os autores se posicionaram desde o surgimento do tema e acompanhar sua evolução. Dessa forma, a seguir, serão apresentados modelos e etapas de gestão da informação.

Por meio da análise sistemática de literatura, exposta na metodologia deste artigo, foi possível sintetizar o trabalho de 44 autores, no período de 1988 a 2017. Os resultados são apresentados no quadro 1 .

Quadro 1 - Artigos referentes às etapas e modelos de gestão da informação

\begin{tabular}{|c|c|c|}
\hline Ano & itores & Etapas de gestão da informação \\
\hline 2017 & Bertoldo & $\begin{array}{l}\text { Caracterização do ambiente organizacional; } \\
\text { Organização e análise; Elaborar alternativas; Plano de } \\
\text { implementação; Avaliação }\end{array}$ \\
\hline 2016 & Małolepsza & $\begin{array}{l}\text { Identificação das necessidades de informação; Aquisição da } \\
\text { informação; Organização e armazenamento da informação; } \\
\text { Desenvolvimento de produtos e serviços informacionais; } \\
\text { Distribuição da informação; Uso da informação }\end{array}$ \\
\hline 2016 & Moreira & 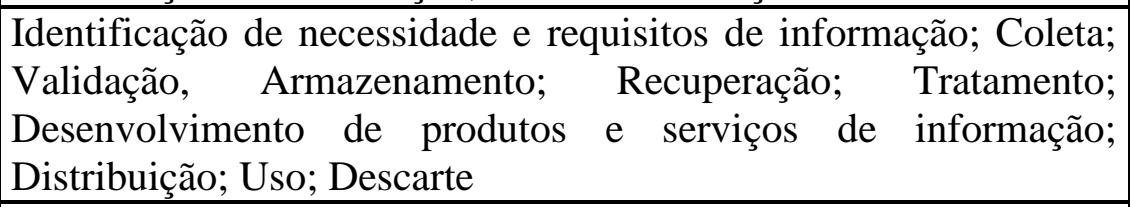 \\
\hline 2015 & De Sordi & $\begin{array}{lll}\text { Identificar/mapear; } & \text { Obter/adquirir; } & \text { Distribuir/partilhar; } \\
\text { Utilizar/aplicar; Aprender/criar; Contribuir; Descartar/despojar }\end{array}$ \\
\hline 2013 & $\begin{array}{l}\text { Starck, } \\
\text { arvakis Rados } \\
\text { e Silva }\end{array}$ & $\begin{array}{l}\text { Identificação das necessidades de informação; Aquisição; } \\
\text { Organização e armazenamento; produtos de informação; } \\
\text { Distribuição; Uso }\end{array}$ \\
\hline 2012 & $\begin{array}{l}\text { Reginato e } \\
\text { Graciolli }\end{array}$ & $\begin{array}{l}\text { Monitoramento dos ambientes interno e externo; Recuperação da } \\
\text { informação; Coleta; Análise; Sistematização da informação; } \\
\text { Compartilhamento; Tomada de decisão }\end{array}$ \\
\hline 2011 & Souza e Duarte & $\begin{array}{l}\text { Determinação das necessidades de informação; Busca; Coleta; } \\
\text { Análise; Seleção; Organização; Armazenamento; Recuperação; } \\
\text { Acesso; Desenvolvimento de produtos e serviços; Distribuição; } \\
\text { Compartilhamento; Disseminação; Utilização/uso }\end{array}$ \\
\hline 2011 & $\begin{aligned} \text { Bast } \\
(\mathrm{M}\end{aligned}$ & $\begin{array}{l}\text { Coleta; Validação; Tratamento; Armazenamento; Recuperação; } \\
\text { Distribuição, Disseminação }\end{array}$ \\
\hline 2010 & Floridi & $\begin{array}{l}\text { Coleta; Registro; Processo; Distribuição/transmissão; Uso; } \\
\text { Reciclagem/Atualização/Descarte }\end{array}$ \\
\hline 2010 & Detlor & $\begin{array}{l}\text { Criação; Aquisição; Organização; Armazenamento; Distribuição; } \\
\text { Uso }\end{array}$ \\
\hline 2009 & & $\begin{array}{l}\text { tificação de necessidades e requisitos; Obtenção; Tratamento; } \\
\text { lazenamento; Distribuição; Uso; Descarte }\end{array}$ \\
\hline 2008 & Lombardi & $\begin{array}{l}\text { Identificação das necessidades de informação; Planejamento; } \\
\text { Aquisição da informação; Representação, organização e }\end{array}$ \\
\hline
\end{tabular}




\begin{tabular}{|c|c|c|}
\hline & & $\begin{array}{l}\text { armazenamento da informação; Distribuição da informação; } \\
\text { Análise e uso da informação }\end{array}$ \\
\hline 2007 & $\begin{array}{l}\text { Monteiro e } \\
\text { Falsarella }\end{array}$ & $\begin{array}{l}\text { Necessidade de informação; Busca; Obtenção; Tratamento; } \\
\text { Armazenamento; Disponibilização; Uso }\end{array}$ \\
\hline 2007 & Arévalo & $\begin{array}{l}\text { Obtenção; } \quad \text { Armazenamento; } \\
\text { Difusão; Tomada de decisão }\end{array}$ \\
\hline 2006 & Tarapanoff & Geração; Coleta; Organização; Disseminação; Uso \\
\hline 2005 & Cândido et al. & $\begin{array}{l}\text { Prospectar/monitorar informação: Captação-coleta-aquisição, } \\
\text { seleção-filtragem; Tratar informação: Análise, interpretação, } \\
\text { transformação, agregar valor; Comunicar informação: Circulação, } \\
\text { difusão, disseminação, transferência, mediação; Usar informação: } \\
\text { Compartilhar/socializar, retroalimentar o sistema }\end{array}$ \\
\hline 2005 & $\begin{array}{l}\text { Gupta, Bhatt, } \\
\text { Kitchens }\end{array}$ & Criar; Manter; Distribuir; Rever e revisionar \\
\hline 2005 & $\begin{array}{c}\text { Laureano e } \\
\text { Moraes }\end{array}$ & Manuseio; Armazenamento; Transporte; Descarte \\
\hline 2004 & $\begin{array}{l}\text { Davenport, } \\
\text { Marchand e } \\
\text { Dickson }\end{array}$ & Coletar; Armazenar; Consultar; Distribuir; Explorar a informação \\
\hline 2004 & Beal & $\begin{array}{l}\text { Identificação das } \text { necessidades e } \\
\text { Tratamento; Armazenamento; Distribuição; Uso; Descarte }\end{array}$ \\
\hline 2004 & EMC & Criar; Proteger; Acessar; Migrar; Arquivar; Descartar \\
\hline 2004 & Le Coadic & Construção; Comunicação; Uso \\
\hline 2003 & Choo & $\begin{array}{l}\text { Identificação das necessidades de informação; Aquisição de } \\
\text { informação; Organização e armazenamento da informação; } \\
\text { Desenvolvimento de produtos e serviços informacionais; } \\
\text { Distribuição; Uso }\end{array}$ \\
\hline 2003 & Cianconi & $\begin{array}{l}\text { Definição das necessidades de } \text { informação; } \\
\text { Armazenamento; Distribuição; Recuperação; Uso }\end{array}$ \\
\hline 2003 & Sêmola & Manuseio; Armazenamento; Transporte; Descarte \\
\hline 2003 & Bueno Campos & Transmissão/Difusão; Medição e gestão \\
\hline 2002 & Miller & $\begin{array}{l}\text { Identificação das necessidades e dos responsáveis pelas decisões; } \\
\text { Coleta; Análise; Disseminação }\end{array}$ \\
\hline 2002 & Marchiori & $\begin{array}{l}\text { Mapeamento das informações necessárias; Coleta; Avaliação da } \\
\text { qualidade; Armazenamento; Distribuição; Uso; Acompanhamento } \\
\text { de resultados }\end{array}$ \\
\hline 2002 & Smit e Barreto & $\begin{array}{l}\text { Sistema de armazenamento, recuperação da informação; Seleção; } \\
\text { Entrada; Classificação; Armazenamento; Recuperação; Uso }\end{array}$ \\
\hline 2002 & Salas & $\begin{array}{l}\text { Produção da informação; Obtenção e distribuição da informação; } \\
\text { Conhecer as necessidades de busca dos trabalhadores; Mapa da } \\
\text { informação; Os metadados }\end{array}$ \\
\hline 2001 & $\begin{array}{l}\text { Marchand, } \\
\text { Kettinger e } \\
\text { Rollins }\end{array}$ & $\begin{array}{l}\text { Detecção/Percepção; Coleta; Organização; Processamento; } \\
\text { Manutenção }\end{array}$ \\
\hline 2000 & $\begin{array}{l}\text { Prost, Raub, } \\
\text { Romhadrt }\end{array}$ & $\begin{array}{l}\text { Identificar; Adquirir; Desenvolver; Partilhar/distribuir; Utilizar; } \\
\text { Reter }\end{array}$ \\
\hline
\end{tabular}




\begin{tabular}{|c|c|l|l|l|}
2000 & $\begin{array}{c}\text { Davenport, } \\
\text { Marchand }\end{array}$ & $\begin{array}{l}\text { Mapear; Adquirir/criar/capturar; Empacotar; Armazenar; } \\
\text { Compartilhar/transferir/aplicar; Inovar/evoluir/transformar }\end{array}$ \\
\hline 2000 & Fernandéz & Identificação; Captura; Organização; Disseminação \\
\hline 1999 & $\begin{array}{c}\text { Bukowitz e } \\
\text { Williams }\end{array}$ & $\begin{array}{l}\text { Obter; Utilizar; Aprender; Contribuir; Avaliar; Construir e } \\
\text { sustentar; Abster-se }\end{array}$ \\
\hline 1999 & $\begin{array}{c}\text { Oliveira e } \\
\text { Amaral }\end{array}$ & Atividades de aquisição; Base de dados; Atividades de utilização \\
\hline 1998 & $\begin{array}{c}\text { Davenport e } \\
\text { Prusak }\end{array}$ & $\begin{array}{l}\text { Determinação de exigências de informação; Obtenção de } \\
\text { informação; Distribuição da informação; Utilização da } \\
\text { informação }\end{array}$ \\
\hline 1998 & $\begin{array}{c}\text { Butcher y } \\
\text { Rowley }\end{array}$ & $\begin{array}{l}\text { Seleção/aquisição; Representação; } \\
\text { Recuperação; Distribuição; Uso }\end{array}$ \\
\hline 1994 & $\begin{array}{l}\text { Planejamento; Organização; Direção; Controle; Reciclagem } \\
\text { Prusak }\end{array}$ & $\begin{array}{l}\text { Identificação de necessidades e requisitos de informação; } \\
\text { Aquisição e coleta de informação; Classificação, armazenamento, } \\
\text { tratamento e apresentação da informação; Desenvolvimento de } \\
\text { produtos e serviços de informação; Distribuição e disseminação } \\
\text { da informação; Análise e uso da informação }\end{array}$ \\
\hline 1994 & $\begin{array}{l}\text { Lesca e } \\
\text { Almeida } \\
\text { serem consumidas de coleta das informações do ambiente externo para } \\
\text { das informaçães coletadas em produtos e serviços destinados à } \\
\text { própria organização; Disponibilização e uso do que fora } \\
\text { produzido internamente ao ambiente externo }\end{array}$ \\
\hline 1992 & Páez Urdaneta & Coletar; Registrar; Processar; Armazenar; Recuperar; Visualizar \\
\hline 1988 & Goldstein & $\begin{array}{l}\text { Obtenção; Interpretação/aprendizagem; Desenvolvimento de } \\
\text { conhecimentos }\end{array}$ \\
\hline
\end{tabular}

Fonte: Elaborado pelos autores.

É importante enfatizar que muitos dos autores estudados não elucidam o significado dos termos por eles utilizados. Por exemplo, existe um grau de subjetividade na tradução dos termos 1. Coleta, obtenção e acesso; 2. Armazenamento e registro; 3. Interpretação, análise, aprendizagem, que em muitas situações podem ser considerados sinônimos. Dessa forma, em alguns momentos, os autores procuraram encontrar os termos mais próximos do português.

\subsection{Análise dos resultados}

O quadro anterior (Quadro 1), além de evidenciar os autores e suas respectivas etapas de gestão da informação, permite algumas inferências com relação ao número de estudos realizados no decorrer dos anos. Os anos 2000 detêm o maior 
número de publicações a respeito do tema, com 33 autores publicados neste período. Os anos 1990 superaram os anos 1980 em quantidade de publicações, sendo nove e uma respectivamente.

Mais do que um levantamento do número de obras por década, é perceptível o crescimento do número de critérios e perspectivas para avaliação, o que confirma os perfis cada vez mais exigentes dos produtores e usuários da informação.

Na tentativa de se compreender algum padrão de publicação a respeito do tema, foi elaborado um levantamento (Quadro 2) contendo a fonte publicadora, o ano de publicação, o país de origem e o número de publicações de cada fonte.

\begin{tabular}{|c|c|c|c|c|}
\hline Nome do periódico & $\begin{array}{l}\text { Tipo de } \\
\text { fonte }\end{array}$ & $\begin{array}{c}\text { Ano de } \\
\text { publicação }\end{array}$ & $\begin{array}{l}\text { País de } \\
\text { origem }\end{array}$ & $\begin{array}{l}N^{\circ} \text { de } \\
\text { artigo }\end{array}$ \\
\hline Universidade Federal de Goiás & Artigo & 2017 & Brasil & 1 \\
\hline $\begin{array}{ll}\text { Universidade } & \text { Federal } \\
\text { Fluminense } & \\
\end{array}$ & Dissertação & 2016 & Brasil & 1 \\
\hline $\begin{array}{l}\text { Czestochowa University of } \\
\text { Technology }\end{array}$ & Artigo & 2016 & Polônia & 1 \\
\hline Administração da informação & Livro & 2015 & Brasil & 1 \\
\hline Biblios & Artigo & 2013 & Brasil & 1 \\
\hline Gestão \& Produção & Artigo & 2012 & Brasil & 1 \\
\hline Liinc em revista & Artigo & 2011 & Brasil & 1 \\
\hline $\begin{array}{l}\text { Proceedings of the } 2 \text { nd } \\
\text { international workshop on } \\
\text { software knowledge }\end{array}$ & Artigo & 2011 & Portugal & 1 \\
\hline $\begin{array}{l}\text { International Journal of } \\
\text { Information Management }\end{array}$ & Artigo & 2010 & Reino Unido & 1 \\
\hline $\begin{array}{l}\text { Information: a very short } \\
\text { introduction }\end{array}$ & Livro & 2010 & USA & 1 \\
\hline $\begin{array}{l}\text { Segurança e Auditoria em } \\
\text { Sistemas da Informação }\end{array}$ & Livro & 2009 & Brasil & 1 \\
\hline $\begin{array}{l}\text { PMKT - Revista Brasileira de } \\
\text { Pesquisas de Marketing }\end{array}$ & Artigo & 2008 & Brasil & 1 \\
\hline $\begin{array}{l}\text { Gestión de la Información, } \\
\text { gestión de contenidos y } \\
\text { conocimiento }\end{array}$ & Artigo & 2007 & Espanha & 1 \\
\hline $\begin{array}{l}\text { Perspectivas em Ciência da } \\
\text { Informação }\end{array}$ & Artigo & 2007 & Brasil & 1 \\
\hline $\begin{array}{l}\text { Inteligência, informação } \mathrm{e} \\
\text { conhecimento }\end{array}$ & Livro & 2006 & Brasil & 1 \\
\hline
\end{tabular}




\begin{tabular}{|c|c|c|c|c|}
\hline $\begin{array}{lll}\text { Revista } & \text { Economia } & \& \\
\text { Tecnologia } & & \\
\end{array}$ & Artigo & 2005 & Brasil & 1 \\
\hline $\begin{array}{l}\text { Journal of Enterprise } \\
\text { Information Management }\end{array}$ & Artigo & 2005 & Reino Unido & 1 \\
\hline DataGramaZero & Artigo & 2005 & Brasil & 1 \\
\hline A ciência da informação & Livro & 2004 & França & 1 \\
\hline $\begin{array}{lll}\text { Gestão } & \text { estratégica } & \text { da } \\
\text { informação } & & \\
\end{array}$ & Livro & 2004 & USA & 1 \\
\hline $\begin{array}{llll}\begin{array}{l}\text { Dominando } \\
\text { informação }\end{array} & \text { a } & \text { gestão } & \text { da } \\
\end{array}$ & Livro & 2004 & USA & 1 \\
\hline EMC Brasil Centro de P\&D & Artigo & 2004 & Brasil & 1 \\
\hline The knowing organization & Livro & 2003 & Canadá & 1 \\
\hline $\begin{array}{l}\text { Universidade Federal do Rio de } \\
\text { Janeiro }\end{array}$ & Tese & 2003 & Brasil & 1 \\
\hline $\begin{array}{lll}\text { Gestão da } & \text { Segurança } & \text { da } \\
\text { Informação } & & \\
\end{array}$ & Livro & 2003 & Brasil & 1 \\
\hline $\begin{array}{l}\text { Journal of Knowledge } \\
\text { Management }\end{array}$ & Artigo & 2003 & Reino Unido & 1 \\
\hline Administração da informação & Livro & 2002 & Brasil & 1 \\
\hline Ciência da Informação & Artigo & 2002 & Brasil & 1 \\
\hline Revista Biblioteca & Artigo & 2002 & Costa Rica & 1 \\
\hline $\begin{array}{l}\text { O milênio da Inteligência } \\
\text { Competitiva }\end{array}$ & Livro & 2002 & USA & 1 \\
\hline Information Orientation & Livro & 2001 & USA & 1 \\
\hline Capital Humano & Artigo & 2000 & Espanha & 1 \\
\hline Managing Knowledge & Livro & 2000 & USA & 1 \\
\hline $\begin{array}{ll}\text { Mastering } & \text { Information } \\
\text { Management } & \\
\end{array}$ & Livro & 2000 & Reino Unido & 1 \\
\hline $\begin{array}{l}\text { The Knowledge Management } \\
\text { Field book }\end{array}$ & Livro & 1999 & Reino Unido & 1 \\
\hline $\begin{array}{lr}\text { Universidade } & \text { Católica } \\
\text { Portuguesa } & - \\
\text { Especializada em Sistemas e TI }\end{array}$ & Conferência & 1999 & Portugal & 1 \\
\hline Conhecimento empresarial & Livro & 1998 & USA & 1 \\
\hline CECAPI-Universidad de Chile & Artigo & 1998 & Chile & 1 \\
\hline Managing Information & Artigo & 1998 & Portugal & 1 \\
\hline Revista de Administração & Artigo & 1994 & Brasil & 1 \\
\hline $\begin{array}{l}\text { Gerenciamento estratégico da } \\
\text { informação }\end{array}$ & Livro & 1994 & USA & 1 \\
\hline $\begin{array}{l}\text { Cuadernos de documentación } \\
\text { multimedia }\end{array}$ & Artigo & 1993 & Espanha & 1 \\
\hline $\begin{array}{l}\text { State of the Modern Information } \\
\text { Professional }\end{array}$ & Artigo & 1992 & Holanda & 1 \\
\hline $\begin{array}{ll}\text { Information Technology } \& \\
\text { People }\end{array}$ & Artigo & 1988 & Reino Unido & 1 \\
\hline
\end{tabular}


Ao observar o período de publicação dos estudos (1988 a 2017), percebe-se que o número de autores e publicações é predominante no Brasil, nos Estados Unidos e no Reino Unido, com 18, oito e seis publicações, respectivamente. Os artigos destacam-se como sendo as principais fontes de publicação sobre o tema.

Extrapolando esta análise e passando a investigar o número de publicações por continentes de origem, é possível inferir que o continente americano contribui com 29 artigos, enquanto o europeu, com 15.

Quanto à incidência de publicações por países ao longo dos anos, nota-se que a maioria dos países passou a contribuir com estudos da área a partir dos anos 2000. Dos 44 artigos elencados na tabela, 77\% (34 artigos) foram elaborados a partir do ano 2000, o que evidencia maior preocupação com o aspecto da confiabilidade e gestão da informação. Especificamente no Brasil, o mesmo fato ocorre, visto que, das 17 publicações mapeadas, somente uma ocorreu neste período.

Outro ponto que merece atenção diz respeito à quantidade e frequência com que os critérios/etapas dos modelos de gestão da informação são mencionados na literatura. Souza e Duarte (2011) identificaram 17 dimensões contempladas nos modelos teóricos de Gestão da Informação. Para este artigo, elaborou-se uma relação (Figura 3) com todos os termos mencionados na literatura pesquisada. Foram analisadas as 44 publicações contidas na Tabela 1 , no período de 1988 a 2017, e elencados 41 termos distintos. 
Figura 3 - Etapas/critérios dos modelos de gestão da informação: número de menções

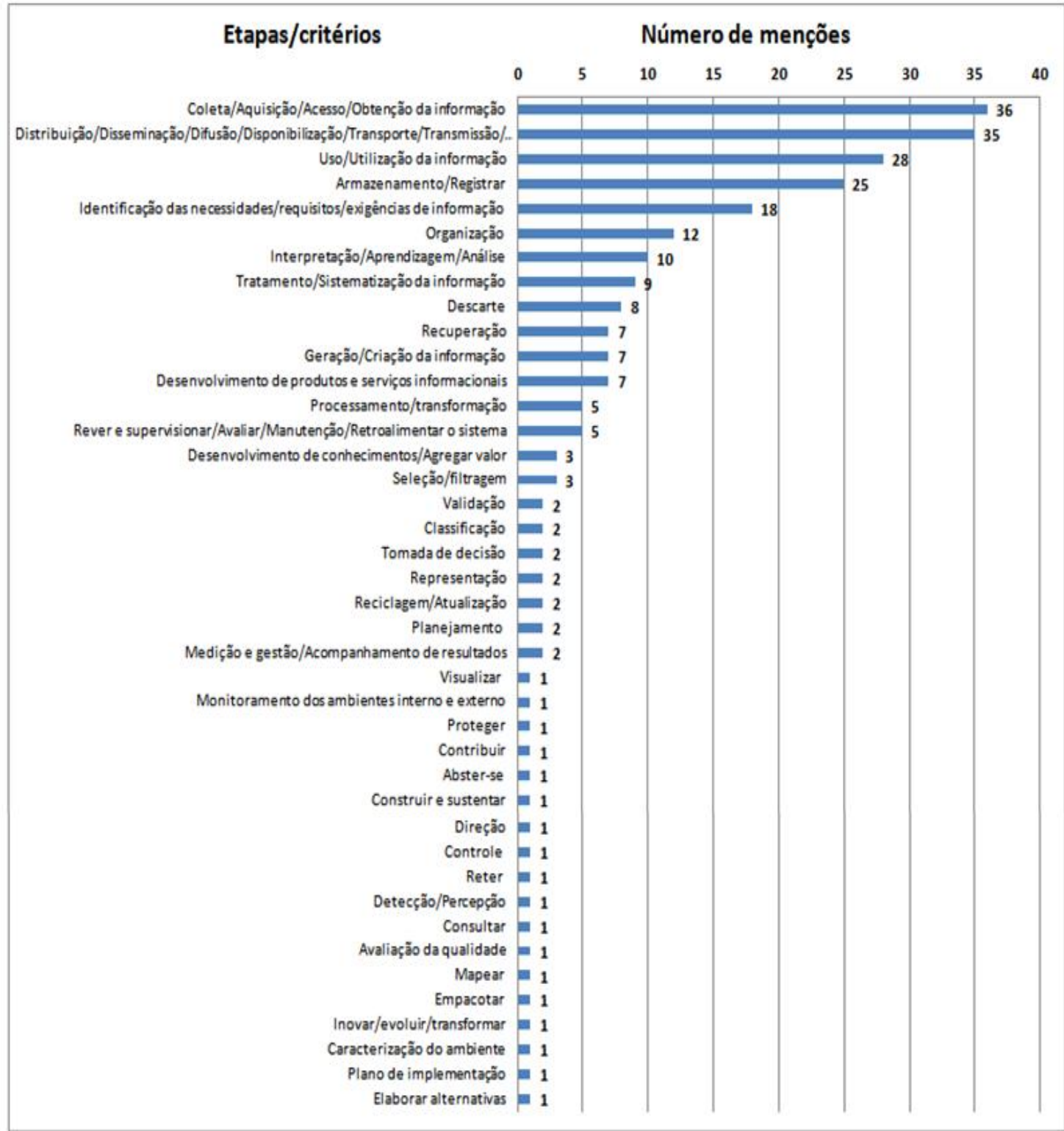

Fonte: Elaborado pelos autores.

Baseando-se nos resultados apresentados na Figura 3, foi realizado um corte, selecionando os 10 critérios com maior índice de menção. Com o intuito de se compreender os propósitos de cada um, faz-se necessário conceituá-los. Segundo Starck, Rados e Silva (2013), o primeiro critério Coleta/Aquisição/Acesso/Obtenção - consiste em adquirir a informação de suas fontes de origem ou coletá-la dos que a desenvolvem para responder as necessidades dos usuários de forma adequada. O segundo critério Distribuição/Disseminação/Difusão - é o processo pelo qual a organização 
difunde e compartilha informações, sempre integrada com os hábitos e as preferências de informação do usuário (CHOO, 2003). Uso/Utilização da informação é o critério de número três e, segundo Davenport (1998), diz respeito ao emprego da informação disponível aos usuários da organização. $\mathrm{O}$ Armazenamento/Registro, critério quatro, é tratado como subsídio da memória das organizações e que a informação, uma vez identificada, passava pela fase de coleta para, finalmente, ser armazenada em sistemas de informação, como arquivos e bancos de dados (SOUZA; DUARTE, 2011). O quinto critério Identificação das necessidades/requisitos de informação - afeta diretamente as demais etapas, pois, segundo Choo (2003), as necessidades de informação surgem de problemas, incertezas e ambiguidades encontradas em situações e experiências organizacionais específicas. A partir do reconhecimento desta deficiência, os usuários procuram informação a fim de compreender e, de posse das informações necessárias, solucionar a situação problema. O critério seis Organização - é o processo de indexação e classificação com vista à posterior e rápida recuperação (DETLOR, 2010). Interpretação/Aprendizagem/Análise critério sete - é o proceso de formação de sentido, de significado (TEIXEIRA, 2003). Para Monteiro e Falsarella (2007), no critério oito Tratamento/Sistematização -, as informações precisam ser depuradas, pois algumas delas não serão de utilidade. Após a depuração, é dado o tratamento às informações selecionadas, dando significado e agregando valor. Segundo De Sordi (2015), Descarte é a propriedade da informação de abster-se de informações e conteúdos não mais necessários ao processo de gestão. Por último, há o critério Recuperação, que, segundo Inweb (2010), indica a atividade de recuperar objetos informacionais armazenados em um meio acessível por computador. Um objeto informacional é geralmente constituído de texto, tais como documentos diversos, páginas Web e livros, embora possa conter outros tipos de conteúdo, tais como imagens, áudios, gráficos e figuras. 


\section{Considerações finais}

A explosão informacional, acarretada em grande parte pelo advento da internet e da evolução das tecnologias de informação e comunicação, faz luz a problemas recorrentes; o excesso de fontes de informação e a falta de confiabilidade das informações obtidas nas fontes digitais (DUTRA; BARBOSA, 2017). Nesse contexto, para que as informações sejam assertivas, são necessários cada vez mais dispositivos de filtros. Buscou-se, dessa forma, pesquisar estudos referentes aos critérios/etapas e modelos para a gestão da informação e, por fim, elencar os termos mais citados entre os diversos autores pesquisados.

Para atingir aos objetivos propostos, foi realizada uma revisão sistemática de literatura dos critérios ou modelos de gestão da informação entre os anos de 1988 a 2017. Foram elencados 44 estudos. Dentre os autores, é relevante informar que os critérios mais frequentes nos modelos estudados são 1. Coleta/Aquisição/Acesso/Obtenção, 2. Distribuição/Disseminação/Difusão, 3. Uso/Utilização, 4. Armazenamento/Registro, 5. Identificação das necessidades/requisitos/exigências, 6. Organização, 7. Interpretação/Aprendizagem/Análise, $\quad 8$. Tratamento/Sistematização, 9. Descarte, 10. Recuperação.

Merece atenção a análise do número de estudos realizados no decorrer dos anos. Não é surpresa que os anos 2000 possuem o maior número de publicações a respeito do tema, visto o constante desenvolvimento dos meios eletrônicos e das tecnologias de informação e comunicação. Por outro lado, é perceptível a pouca evolução no volume de novos critérios e etapas para a gestão da informação, o que evidencia uma grande influência dos estudos precursores a respeito do tema. Ao se analisar os estudos elencados na tabela 1 , percebe-se que autores como McGee e Prusak (1994), Davenport (1998) e Choo (2003) serviram de base para a elaboração de novos modelos de gestão da informação.

Mais do que uma revisão sistemática, o estudo auxiliou na percepção de aspectos relevantes a respeito da gestão da informação. Em primeiro lugar, percebe-se a inexistência de um modelo de gestão da informação aceito de maneira consensual entre os estudiosos. Como consequência, os critérios 
propostos pelos autores são subjetivos e condizentes com a realidade de cada problema pesquisado. É relevante ainda a menção a critérios pouco mencionados nos modelos pesquisados, mas importantes na literatura, como 1 . Medição/acompanhamento de resultados e 2. Rever/ Supervisionar/Avaliar/Manutenção/Retroalimentar o sistema. São etapas cruciais no processo de gestão da informação e estranha-se o fato de serem pouco mencionadas nos modelos estudados neste artigo.

\section{Referências}

ARAUJO, Nelma Camêlo; FACHIN, Juliana. Evolução das fontes de informação. BIBLOS - Revista do Instituto de Ciências Humanas e da Informação, Rio Grande, v. 29, n. 1, 2015. Disponível em: http://hdl.handle.net/20.500.11959/brapci/23206. Acesso em: 05 jul. 2019.

ARAÚJO, Wagner Junqueira et al. Validação do mapeamento de fluxos de informação em processos organizacionais: uma abordagem com foco arquivístivo. In: ENCONTRO NACIONAL DE PESQUISA EM CIÊNCIA DA INFORMAÇÃO, 19., 2018, Londrina. Anais [...]. Londrina: UEL, 2018. Disponível em: http://hdl.handle.net/20.500.11959/brapci/102977. Acesso em: 08 jul. 2019.

ARTILES VISBAL, Sara. La gestión documental, de información y el conocimiento en la empresa: el caso de Cuba. ACIMED, Ciudad de La Habana, v. 19 , n. 5, mayo 2009.

BARBOSA, Evandro Henrique Santos. et al. As mídias sociais como ferramenta do processo de inteligência competitiva e gestão do conhecimento. In:

ENCONTRO NACIONAL DE PESQUISA EM CIÊNCIA DA

INFORMAÇÃO, 19., 2018, Londrina. Anais [...]. Londrina: UEL, 2018.

BARBOSA, Ricardo Rodrigues. Monitoração ambiental: uma visão interdisciplinar. Revista de Administração, São Paulo, v. 32, n. 4, p. 42-53, out./dez. 1997.

BARBOSA, Ricardo Rodrigues. Gestão da Informação e Gestão do Conhecimento: origens, polêmicas e perspectivas. Informação \& Informação, v. 13, n. esp., p. 1-25, 2008.

BARBOSA, Ricardo Rodrigues; SEPULVEDA, Maria Inês Moreira; COSTA, Mateus Uerlei Pereira da. Gestão da informação e do conhecimento na era do compartilhamento e da colaboração. Informação \& Sociedade: Estudos, João Pessoa, v. 19, n. 2, p. 13-24, maio/ago. 2009. 
BAWDEN, David; ROBINSON, Lyn. The dark side of information: overload, anxiety and other paradoxes and pathologies. Journal of Information Science, v. 35, n. 2, p. 180-191, 2009.

BERGERON, Patrice. Information resources management. Annual Review of Information Science and Technology, v. 31, p. 263-300, 1996.

BORGES, Mônica Erichsen Nassif; CARVALHO, Natália Guiné de Mello. Produtos e serviços de informação para negócios no Brasil: características. Ciência da Informação, Brasília, v. 27, n. 1, p. 76-81, jan./abr. 1998.

CALAZANS, Angélica Toffano Seidel. Conceitos e uso da informação organizacional e informação estratégica. Revista Transinformação, Campinas, v. 18, n. 1, p. 63-70, jan./abr. 2006.

CENDÓN, Beatriz Valadares. A Internet. In: CAMPELLO, B. S.; CENDÓN, Beatriz Valadares; KREMER, S. M. Fontes de informação para pesquisadores e profissionais. Belo Horizonte: UFMG, 2000. p. 275-300.

CHAMUSCA, Marcelo; CARVALHAL, Márcia. Comunicação e marketing digitais: conceitos, práticas, métricas e inovações. Salvador: Edições VNI, 2011.

CHOO, Chun Wei. A organização do conhecimento: como as organizações usam a informação para criar significado, constituir conhecimento e tomar decisões. Tradução: Eliana Rocha. São Paulo: Editora SENAC, 2003.

CHORLEY, Richard; HAGGET, Peter. Modelos, paradigmas e a nova geografia. In: CHORLEY, R. H.; HAGGET, P. Modelos sócios - econômicos em geografia. Rio de Janeiro: Livros Técnicos e Científicos / USP, 1975. p. 122.

CUNHA, Murilo Bastos da. Para saber mais: fontes de informação em ciência e tecnologia. Brasília: Briquet de Lemos Livros, 2001.

DAVENPORT, Thomas. Ecologia da informação. São Paulo: Futura, 1998.

DE SORDI, José Osvaldo. Administração da informação: fundamentos e práticas para uma nova gestão do conhecimento. São Paulo: Saraiva, 2015.

DETLOR, Brian. Information Management. Journal of Information Management. 30:2 (Apr. 2010) 103-108.

DUTRA, Frederico Giffoni de Carvalho. Avaliação de conteúdo e serviços de informação: um estudo das fontes de informação para monitoramento dos clientes do mercado livre de energia no Brasil. 2014. Dissertação (Mestrado em Gestão da Informação e do Conhecimento) - Escola de Ciência da Informação, Universidade Federal de Minas Gerais, Belo Horizonte, 2014. 
DUTRA, Frederico Giffoni de Carvalho; BARBOSA, Ricardo Rodrigues. Modelos e critérios para avaliação da qualidade de fontes de informação: uma revisão sistemática de literatura. Informação \& Sociedade: Estudos, João Pessoa, v. 27, p. 19-33, 2017.

FONSECA, Flávia de Souza Magalhães; BARBOSA, Ricardo Rodrigues; PEREIRA, Frederico César. Uso de fontes de informação por gestores de startups. Perspectivas em Ciência da Informação, Belo Horizonte, n. 1, v. 24, p. 84-102, 2019.

FONTE. In: FERREIRA, Aurélio Buarque de Holanda. Dicionário Aurélio Básico da Língua Portuguesa. Disponível em: http://dicionariodoaurelio.com/fonte. Acesso em: 15 mar. 2018.

GALVÃO, Alexander Patêz. A informação como commodity: mensurando o setor de informações em uma nova economia. Ciência da Informação, Brasília, v. 28, n. 1, p. 67-71, 1999.

INWEB. Recuperação da informação. Disponível em: http://www.inweb.org.br/linhasde-pesquisa-inweb/recuperacao-de-informacao/. Acesso em: 1 jan. 2019.

LAUDON, Kenneth; LAUDON, Jane. Sistemas de gerenciamento de informação: organização e tecnologia. New Jersey: Prentice-Hall, 1996.

LESCA, Humbert; ALMEIDA, Fernando C. Administração estratégica da informação. Revista de Administração, São Paulo, v. 29, n. 3, p. 66-75, jul./set. 1994.

MARCHIORI, Patrícia Zeni. A ciência e a gestão da informação: compatibilidades no espaço profissional. Ciência da Informação, Brasília, v. 31, n. 2, p. 72-79, maio/ago. 2002.

MARTELETO, Regina Maria. Redes sociais, mediação e apropriação de informações: situando campos, objetos e conceitos na pesquisa em Ciência da Informação. Tendências da Pesquisa Brasileira em Ciência da Informação, João Pessoa, v. 3, n. 1, p. 27-46, 2010.

MARTINS, Sérgio de Castro. Gestão da informação: estudo comparativo de modelos. 2014. Dissertação (Mestrado em Ciência da Informação)- Programa de Pós-Graduação (stricto-sensu) em Ciência da Informação, Universidade Federal Fluminense, Rio de Janeiro, 2014.

MARTINS, Sérgio de Castro; CIANCONI, Regina de Barros. Gestão da informação: estudo comparativo de modelos sob a perspectiva integrativa dos recursos de informação. In: ENCONTRO NACIONAL DE PESQUISA EM CIÊNCIA DA INFORMAÇÃO, 14., 2013, Florianópolis. Anais [...]. Florianópolis: Universidade Federal de Santa Catarina, 2013. p.1-6. 
McGEE, John Vernon; PRUSAK, Laurence. Gerenciamento estratégico da informação: aumente a competitividade e a eficiência de sua empresa utilizando a informação como uma ferramenta estratégica. Rio de Janeiro: Campus, 1994.

MENDONÇA, Thais Carrier; VARVAKIS, Gregório. Análise do uso da informação para tomada de decisão gerencial em gestão de pessoas: estudo de caso em uma instituição bancária. Perspectivas em Ciência da Informação, Belo Horizonte, v. 23, n. 1, p. 104-119, 2018.

MONTEIRO, Nabor Alves; FALSARELLA, Orandi Mina. Um modelo de gestão da informação para aprendizagem organizacional em projetos empresariais. Perspectivas em Ciência da Informação, Belo Horizonte, v. 12, n. 2, p. 81-97, 2007.

OLIVEIRA, Marlene; BERTUCCI, Maria da Graça Eulálio. A pequena e média empresa e a gestão da informação. Informação \& Sociedade, João Pessoa, v. 13, n. 2, p. 1-16, 2003.

PACHECO, Cíntia Gomes; VALENTIM, Marta Lígia Pomim. Informação e conhecimento como alicerces para a gestão estratégica empresarial: um enfoque nos fluxos e fontes de informação. In: VALENTIM, Marta (org.). Gestão, mediação e uso da informação. São Paulo: Cultura Acadêmica, 2010. p. 319341.

RECUERO, Raquel. Redes sociais na internet. Porto Alegre: Sulina, 2009. 191 p.

REZENDE, Yara. Informação para negócios: os novos agentes do conhecimento e a gestão do capital intelectual. Ciência da Informação, Brasília, v. 31, n. 1, p. 75-83, jan./abr. 2002.

RODRIGUES, Charles; BLATTMANN, Ursula. Gestão da informação e a importância do uso de fontes de informação para geração de conhecimento. Perspectivas em Ciência da Informação, v. 19, n. 3, p. 4-29, mai./ago. 2007.

RODRIGUES, Charles; BLATTMANN, Ursula. Gestão da informação e a importância do uso de fontes de informação para geração de conhecimento. Perspectivas em Ciência da Informação, Belo Horizonte, v. 19, n. 3, p. 4-29, jul./set. 2014.

RODRIGUES, Jorge Luis; TOMAÉL, Maria Inês. As redes sociais e o uso da informação entre os pesquisadores de alimentos funcionais da UEL. Revista Digital de Biblioteconomia \& Ciência da Informação, Campinas, v. 6, n. 1, p. 15-37, jan./jun. 2008.

ROSSETTI, Adroaldo et al. A organização baseada no conhecimento: novas estruturas, estratégias e redes de relacionamento. Ciência da Informação, Brasília, v. 37, n. 1, p. 61-72, jan./abr. 2008. 
SAVOLAINEN, Reijo. Information Behavior and Information Practice: Reviewing the "Umbrella Concepts" of Information-Seeking Studies. Library Quarterly, Chicago, v. 77, n. 2, p. 109-132, 2007.

SAYÃO, Luis Fernando. Modelos teóricos em Ciência da Informação: abstração e método científico. Ciência da Informação, Brasília, v. 30, n. 1, p. 82-91, 2001.

SILVA, Alzira Karla Araújo. Gestão da Informação. João Pessoa, 2006. (Apostila)

SOUZA, Irma Gracielle Carvalho de Oliveira; DUARTE, Emeide Nóbrega. 2011. Dimensões de um modelo de gestão da informação no campo da Ciência da Informação: uma revelação da produção científica do ENANCIB. Liinc em revista, Rio de Janeiro, v. 7, n. 1, p. 152-169, mar. 2011.

STARCK, Katia Regina; VARVAKIS RADOS, Gregorio Jean; SILVA, Edna Lucia. Os estilos e os modelos de gestão da informação: alternativas para a tomada de decisão. Biblios, v. 52, p. 59-73, 2013.

SUGAHARA, Cibele Roberta; VERGUEIRO, Waldomiro. Aspectos conceituais e metodológicos de redes sociais e sua influência no estudo de fluxos de informação. Revista Digital de Biblioteconomia \& Ciência da Informação, Campinas, v. 7, n. 2, p. 102-117, jan./jun. 2010.

TAKEUCHI, Hirotaka; NONAKA, Ikujiro. Gestão do conhecimento. Porto Alegre: Bookman, 2008.

TARAPANOFF, Kira. Informação, conhecimento e inteligência em corporações: relações de complementaridade. In: TARAPANOFF, K. (org.). Inteligência, informação e conhecimento. Brasília: IBICT, UNESCO, 2006. p. 19-35.

TEIXEIRA, Enise Barth. A Análise de Dados na Pesquisa Científica.

Desenvolvimento em Questão, Ijuí, ano 1, n. 2, p. 177-201, jul./dez. 2003.

VALENTIM, Marta Lígia Pomim. O custo da informação tecnológica. São Paulo: Polis, 1997.

VALENTIM, Marta Lígia Pomim. Inteligência Competitiva em Organizações: dado, informação e conhecimento. DataGramaZero, Rio de Janeiro, v. 3, n. 4, ago. 2002.

VANCE, Cecilia de Salles. A internet como fonte de informações para a competitividade das empresas do setor elétrico brasileiro. 2000. Dissertação (Diplome D'estudes approfondies en information scientifique et technique veille technologique) - Faculté des Sciences et Techniques de St. Jérôme, Marseille. 2000. 


\title{
Models and stages for information management: a systematic literature review
}

\begin{abstract}
The article reports the results of a literature review on models and stages used for the information management. A bibliographic search was conducted in three idioms (Portuguese, Spanish and English) to analyse the scientific production related to sources of information, information management as well as the criteria and models used for their management. After a research on articles and other publications in the period 1972 to 2019, the results indicate the existence of 44 models. The most frequently mentioned criteria were also identified. It was found that there are 38 distinct terms, highlighting the following: colect/aquision, distribution, use, store/record, organization, learning/analyze, treatment, discard, retrieval.
\end{abstract}

Keywords: Information management. Models. Stages. Information sources.

Recebido: 14/04/2019

Aceito: 17/07/2019 